\title{
Tuberculose gastrointestinal mimetizando neoplasia de cólon
}

\section{Gastrointestinal tuberculosis mimetizing colon neoplasia}

Ingrid de Lima Carlos ${ }^{1}$. Gabriela Studart Galdino ${ }^{1,2}$. Paulo Roberto de Arruda Tavares ${ }^{1,2}$. Ítalo Gustavo Lima Monteiro $^{1}$. Lara Andrade Vieira ${ }^{1}$. Giovanna Peressin da Paz ${ }^{1}$. Maria Carolina Nunes Albano de Meneses ${ }^{1}$.

1 Hospital Universitário Walter Cantídio (HUWC), Fortaleza, Ceará, Brasil. 2 Universidade Federal do Ceará (UFC), Fortaleza, Ceará, Brasil.

\section{RESUMO}

Introdução: a tuberculose (TB) é uma doença de alta prevalência em todo o mundo. A forma extrapulmonar da doença representa cerca de $20 \%$ dos casos de TB, aproximadamente $10 \%$ correspondendo a TB abdominal. Apesar disso, o diagnóstico da TB abdominal continua sendo um desafio. Relato: paciente feminina, 49 anos, com lesão em cólon sugestiva de neoplasia, que foi submetida a histopatológico. No resultado, foi evidenciado que a doença, na verdade, tratava-se de uma tuberculose gastrointestinal. Discussão: A TB gastrointestinal tem uma apresentação clínica variada, podendo simular diversas doenças, com muitos diagnósticos tardios, acarretando em elevada morbidade. Os exames diagnósticos são inespecíficos e é necessária alta suspeição clínica. Conclusão: Deve-se sempre considerar a tuberculose como diagnóstico diferencial em nosso meio, devido a sua alta incidência e pela apresentação clínica pouco específica.

Palavras-chave: Tuberculose. Diagnóstico. Neoplasias intestinais.

\begin{abstract}
Introduction: Tuberculosis (TB) is a highly prevalent disease worldwide. The extrapulmonary form of the disease represents about $20 \%$ of TB cases, with approximately $10 \%$ of those corresponding to abdominal TB. Nevertheless, the diagnosis of abdominal TB remains a challenge. Report: A 49-year-old female patient with a colon lesion suggestive of cancer who underwent histopathology. As a result, it was shown that the disease was actually gastrointestinal tuberculosis. Discussion: Gastrointestinal TB has a varied clinical presentation and can simulate various diseases, with many delayed diagnoses, leading to high morbidity. Diagnostic tests are nonspecific and high clinical suspicion is required. Conclusion: Tuberculosis should always be considered as a differential diagnosis in our country, due to its high incidence and non specific clinical presentation.
\end{abstract}

Keywords: Tuberculosis. Diagnosis. Intestinal neoplasms.

Autor correspondente: Ingrid de Lima Carlos, Rua Pastor Samuel Munguba, 1290, Rodolfo Teófilo, Fortaleza, Ceará. CEP: 60430-372. Telefone: +55 84 99660-6800. E-mail: ingridlimaflor@gmail.com

Conflito de interesses: Não há qualquer conflito de interesses por parte de qualquer um dos autores.

Recebido em: 28 Jan 2020; Revisado em: 03 Out 2020; Aceito em: 09 Out 2020. 


\section{INTRODUÇÃO}

A tuberculose (TB) é uma doença infectocontagiosa, causada pelo Mycobacterium tuberculosis, de alta incidência em todo o mundo, com cerca de 10 milhões de pessoas adoecendo a cada ano, sendo uma das 10 principais causas de morte. ${ }^{1}$ Somente no Brasil foram notificados e confirmados, no ano de 2018, 91131 casos de TB, dos quais, 11657 casos de doença extrapulmonar. ${ }^{2}$ A forma extrapulmonar representa cerca de $20 \%$ dos casos de TB, com aproximadamente $10 \%$ correspondendo a TB abdominal. Apesar de sua alta incidência, o diagnóstico da TB abdominal é um desafio, pois os sintomas típicos e os testes diagnósticos são inespecíficos. ${ }^{3}$

Relatamos um caso de TB gastrointestinal em uma paciente não infectada pelo vírus HIV e encaminhada para investigação de síndrome febril com perda ponderal marcante.

Este estudo foi aprovado Comitê de Ética do Hospital Universitário Walter Cantídio, Fortaleza, CE, Brasil, sob protocolo número 018.10.2019, de acordo com a Resolução 466/12 do Conselho Nacional de Saúde.

\section{RELATO DE CASO}

Paciente feminina, parda, 49 anos, agricultora, procurou ambulatório de clínica médica com astenia, inapetência, febre de até $39^{\circ} \mathrm{C}$, sem calafrios, cerca de duas a três vezes por semana, associada à sudorese noturna há cerca de um ano. Além disso, apresentou, cerca de sete meses após início do quadro, diarreia pastosa, com fezes escurecidas e odor fétido por um mês, que cessou espontaneamente. Relatava ainda perda ponderal de $13 \mathrm{~kg}$ nesse período (de $49 \mathrm{~kg}$ para 36kg: aproximadamente $26 \%$ do peso corporal). Ao exame físico admissional, encontrava-se com regular estado geral, hipocorada $(3+/ 4+)$ e emagrecida (IMC: $\left.16,4 \mathrm{~kg} / \mathrm{m}^{2}\right)$. Na história pregressa, é ex-tabagista (cerca de 30 maços/anos) e tem uma irmã falecida por câncer de estômago aos 49 anos de idade.

Durante investigação diagnóstica, sorologias para vírus $\mathrm{HIV}$, sífilis e hepatites B e C foram negativas. A endoscopia digestiva alta e mamografia mostraram-se normais. Tomografia computadorizada (TC) de tórax evidenciou agrupamentos de micronódulos centrolobulares nas porções superiores bilateralmente, e, no lobo superior esquerdo associava-se à discreta consolidação focal, além de linfonodo mediastinal calcificado e granulomas residuais no lobo superior direito e inferior contralateral. Diante dos achados pulmonares, apesar da ausência de sintomas, a paciente foi submetida a broncoscopia com coleta de lavado broncoalveolar, pesquisa direta de microorganismos, culturas e realização de teste rápido molecular para TB todos resultaram negativos.

A TC de abdome e pelve mostrou espessamento parietal íleo-cólico com discreta linfadenopatia mesentérica (Figura 1). Para melhor elucidação, foi realizada colonoscopia que evidenciou extensa lesão vegetante em região de cólon ascendente, friável, ocupando toda a circunferência da alça, causando estreitamento da luz e impedindo passagem do aparelho, sem visualização de limites proximais da mesma, sendo bastante sugestiva de lesão neoplásica (Figura 2). A dosagem de antígeno carcinoembrionário estava pouco acima do limite superior da normalidade - 3,2 ng/mL (referência: 3 $\mathrm{ng} / \mathrm{mL})$.

Figura 1. TC de abdome mostrando espessamento parietal íleo-cólico (seta).

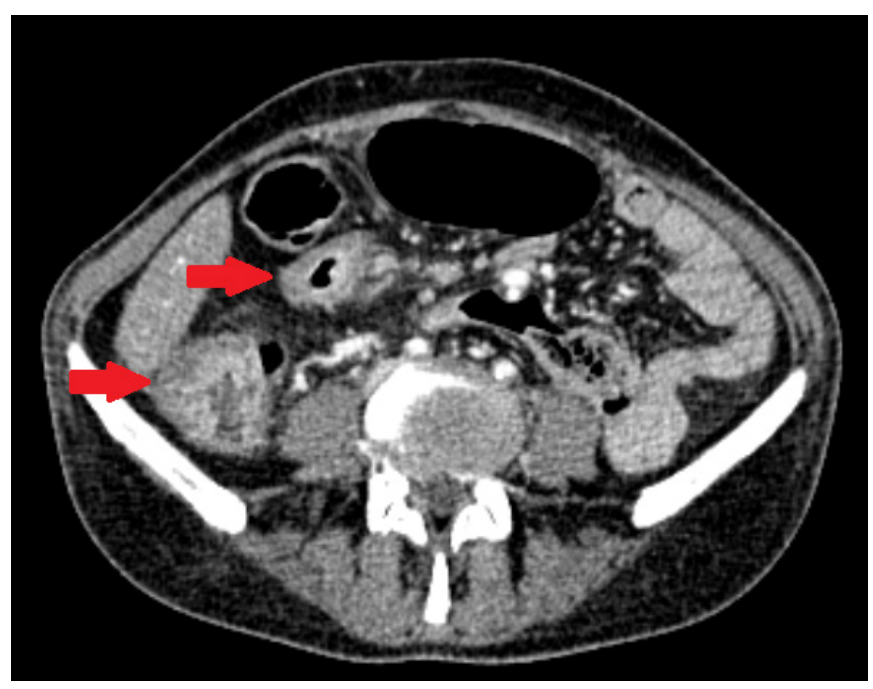

Figura 2. Colonoscopia evidenciando lesão vegetante em cólon ascendente (seta).

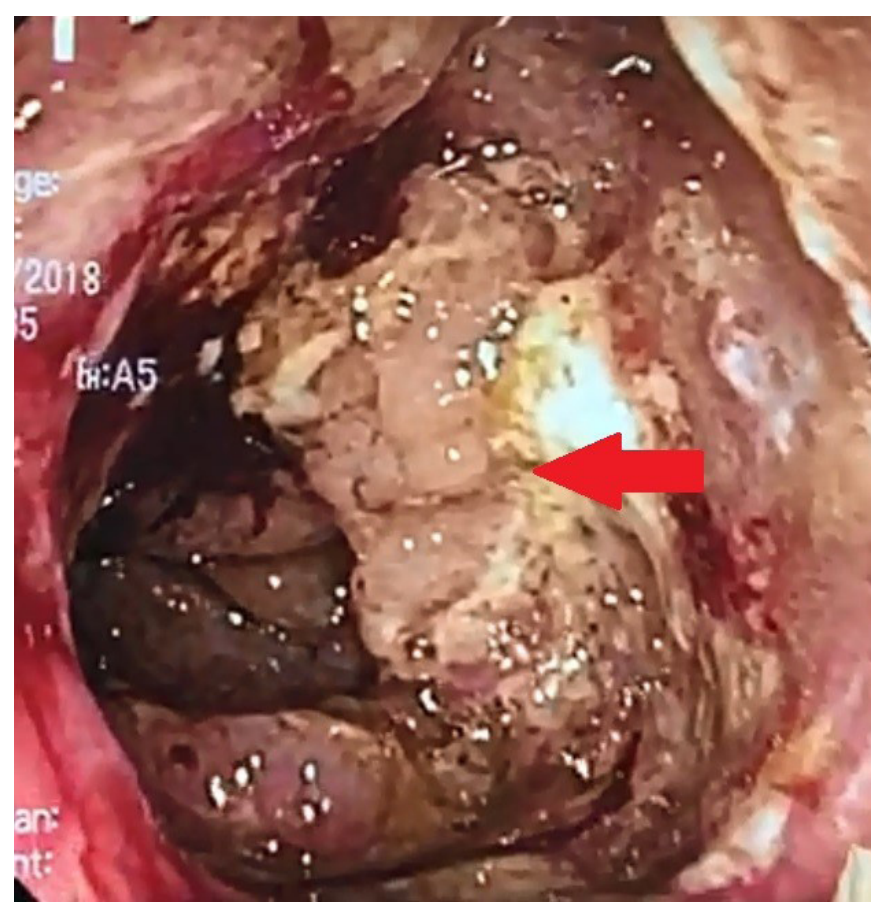


O resultado de histopatológico da lesão de cólon mostrou colite crônica granulomatosa de padrão tuberculoide, com pesquisa negativa para fungos e para bacilos álcool-ácido resistentes e ausência de neoplasia. O tratamento padrão para tuberculose foi instituído - rifampicina, isoniazida, pirazinamida e etambutol por 2 meses, seguido de rifampicina e isoniazida 4 meses. Durante o seguimento, a paciente evoluiu afebril e recuperou o peso corporal.

\section{DISCUSSÃO}

A TB abdominal é uma infecção causada pelo M. tuberculosis que envolve os tratos gastrointestinal e urinário, como também, peritônio, gânglios linfáticos ou órgãos sólidos (fígado, baço e pâncreas). ${ }^{4}$ Devido a sua apresentação clínica variada é, muitas vezes, diagnosticada tardiamente, acarretando em elevada morbidade. ${ }^{5}$

Existem quatro tipos de apresentação da doença: linfadenopatia, peritoneal, gastrointestinal e visceral. Dessas, a apresentação mais comum é a primeira, marcada pelo acometimento de linfonodos na cavidade abdominal. $\mathrm{Na}$ forma gastrointestinal, a localização mais comum é a ileocecal (64\% dos casos), seguida de jejuno e cólon. ${ }^{5}$ No caso apresentado, o acometimento era localizado no cólon ascendente, por ser menos comum, contribuiu para o desafio diagnóstico.

A infecção abdominal se dá através da ingestão de escarro ou leite contaminados, disseminação hematogênica de outros focos, disseminação linfática e por contiguidade de órgãos adjacentes. ${ }^{5}$ Os sintomas são geralmente inespecíficos, como dor abdominal, perda de peso, anorexia e febre, ${ }^{6}$ sendo uma doença simuladora, pois pode acometer diversos órgãos abdominais e poupar o pulmão, com necessidade de alta suspeição para o diagnóstico. ${ }^{3}$

O quadro clínico da TB abdominal pode mimetizar diversas patologias, como doença inflamatória intestinal, malignidade do cólon ou infecções gastrointestinais. ${ }^{4}$ Os achados de imagem também podem ser indistinguíveis e o histopatológico passa a ser mandatório em algumas situações. ${ }^{6}$ No caso apresentado, os sintomas eram inespecíficos, os exames radiológicos não elucidativos, a infecção pulmonar ativa foi

\section{REFERÊNCIAS}

1. World Health Organization. Global tuberculosis reports 2019 [Internet]. Geneva: World Health Organization; 2019 [acesso em: 01 fev 2019]. Disponível em: https://www.who.int/tb/publications/ global_report/en/

2. Brasil. Ministério da Saúde. Departamento de Informática do Sistema Único de Saúde. Informações de Saúde. Epidemiológicas e morbidade. Casos de tuberculose - desde 2001 [Internet]. Brasília: Ministério da Saúde; 2008 [acesso em: 01 fev 2019]. Disponível em: http://tabnet.datasus.gov.br/cgi/tabcgi.exe?sinannet/cnv/tubercbr.def

3. Abu-Zidan FM, Sheek-Hussein M. Diagnosisof abdominal descartada e a lesão na colonoscopia era altamente sugestiva de malignidade.

O diagnóstico de TB abdominal continua sendo um desafio, uma vez que as lesões muitas vezes são de difícil acesso, bem como são paucibacilares. ${ }^{7}$ Os exames radiológicos, procedimentos endoscópicos e cirúrgicos podem ser utilizados para o diagnóstico, além da realização de pesquisas microbiológicas e histopatológica do material obtido. Porém, não existe um teste "padrão-ouro". ${ }^{8}$ A conduta deve ser individualizada. Os exames de imagem ajudam na definição e caracterização do acometimento. A tomografia computadorizada de abdome e pelve é o exame de escolha para avaliação da extensão e do tipo de lesão abdominal. Os achados desses exames são bastante variados e pouco específicos, desde espessamentos da parede intestinal, ulcerações, fibrose, estenoses, linfonodomegalias até implantes peritoneais. ${ }^{3,8}$

A cultura de material de biópsia é positiva em apenas 10\% a $20 \%$ dos casos e requer um tempo mínimo para positivação. A reação em cadeia da polimerase (PCR), tem baixa sensibilidade e especificidade para os focos abdominais. ${ }^{7}$ Diante de tamanha dificuldade para firmar o diagnóstico, portanto, é necessária alta suspeição clínica e a propedêutica deve ser adaptada para cada indivíduo, iniciando com os procedimentos menos invasivos. ${ }^{8}$

O Ministério da Saúde e a Organização Mundial de Saúde recomendam que o tratamento da TB gastrointestinal seja realizado por 6 meses: dois meses com rifampicina, isoniazida, pirazinamida e etambutol, seguido de quatro meses com rifampicina e isoniazida. ${ }^{1,9} \mathrm{Em}$ determinados casos, alguns médicos prologam o tratamento para 9 ou 12 meses, porém não foi observado aumento da eficácia do tratamento. Uma minoria dos pacientes necessitará de tratamento cirúrgico. ${ }^{5}$

\section{CONCLUSÃO}

O presente caso ilustra o desafio diagnóstico na tuberculose abdominal. A sintomatologia pouco específica aliada a achados de imagem que, por vezes, mimetizam outras patologias reafirmam a necessidade de alta suspeição clínica, principalmente, em nosso meio, onde a prevalência da tuberculose persiste muito alta. tuberculosis: lessonslearned over 30 years: pectoral assay. World J Emerg Surg. 2019;14:33.

4. Shreshtha S, Ghuliani D. Abdominal tuberculosis: a retrospective analysis of 45 cases. Indian J Tuberc. 2016;63(4):219-24.

5. Debi U, Ravisankar V, Prasad KK, Sinha SK, Sharma AK. Abdominal tuberculosisofthe gastrointestinal tract: revisited. World J Gastroenterol. 2014;20(40):14831-40.

6. Schmidt-Lauber C, Jacobi J, Polifka I, Hilgers KF, Wiesener MS. Suspected colonic cancer turns out to be disseminated tuberculosis 
in a kidney transplant recipient: a case report. Medicine (Baltimore). 2019;98(36):e16995.

7. Shinga BW, Shinga BW, Dièye A, Badiane NM, Lakhe NA, Diallo VM, et al. [Intestinal tuberculosis revealed by acute bowel obstruction during paradoxical reaction to antituberculosis treatment in na immunocompetent patient: about a case and literature review]. Pan Afr Med J. 2019;32:173. Article in French.
8. Fahlbusch T, Braumann C, Uhl W. [Treatmentof abdominal tuberculosis: background, diagnostics and treatment of a global problem]. Chirurg. 2019;90(10):818-22. Article in German.

9. Ministério da Saúde. Manual de recomendações para o controle da tuberculose no Brasil [Internet]. Brasília: Ministério da Saúde; 2019 [acesso em: 01 fev 2019]. Disponível em: http://bvsms.saude.gov. br/bvs/publicacoes/manual_recomendacoes_controle_tuberculose brasil_2_ed.pdf

\section{Como citar:}

Carlos IL, Galdino GS, Tavares PR, Monteiro IG, Vieira LA, Paz GP, et al. Tuberculose gastrointestinal mimetizando neoplasia de cólon. Rev Med UFC. 2021;61(1):1-4. 